\title{
Spatial Spillover Transmission Effects of Financial Development on Economic-Zone Financial Efficiency in China
}

\author{
Kai Chang $\mathbb{D}^{1,2}{\text { Zesheng } \mathrm{Li}^{3}{ }^{3} \text { and Yu Long }}^{1}$ \\ ${ }^{1}$ School of Finance and Business, Shanghai Normal University, Shanghai 200234, China \\ ${ }^{2}$ Global Capital Innovation Research College, Shanghai Normal University, Shanghai 200234, China \\ ${ }^{3}$ Pratt School of Engineering, Duke University, Durham, NC 27708, USA \\ Correspondence should be addressed to Kai Chang; kchang16@163.com
}

Received 7 May 2021; Revised 26 October 2021; Accepted 4 December 2021; Published 4 January 2022

Academic Editor: Wei Li

Copyright ( $\odot 2022$ Kai Chang et al. This is an open access article distributed under the Creative Commons Attribution License, which permits unrestricted use, distribution, and reproduction in any medium, provided the original work is properly cited.

\begin{abstract}
This article attempts to fill important knowledge gaps to explore the spatial spillover effects of financial markets on regional financial efficiency in eight economic zones using three-stage superefficiency data envelopment analysis (DEA) and Durbin's spatial econometric model. The average financial efficiencies in the North coast, East coast, and South coast economic zones reach the superefficiency DEA relatively efficient level, while the average financial efficiencies in the Northeast, Middle Yellow River, Middle Yangtze River, and large West-south and West-north economic zones reach the superefficiency DEA relatively inefficient level. Except for the North coast economic zone, seven equity markets have significant impacts on regional financial efficiency, and local equity markets in the Northeast, South coast, Middle Yellow River, and Middle Yangtze River economic zones generate significant spatial spillover effects on neighboring regions' financial efficiency. Local credit markets only in the Northeast and South coast economic zones have significant spatial spillover influences on neighboring regions' financial efficiency. Debt markets in the North coast, East coast, South coast, Middle Yangtze River, and large West-south economic zones have significant influences on regional financial efficiency, and local debt markets in the East coast and Middle Yangtze River economic zones generate significant spatial spillover effects on neighboring regions' financial efficiency.
\end{abstract}

\section{Introduction}

Understanding the financial market development and regional allocation efficiency of financial resources in China is a topic of increasing interest among policymakers and academic scholars. China is an emerging country with a government-led market economy. The financial system is reflected in the government's efforts to promote economic growth and exploit the utility of resource allocation. In China, different local governments exhibit significant divergence in financial resource competition and financial market development. Such divergence influences financial resource allocation efficiency and spatial spillover effects among different regions. The main purpose of this article is to explore whether different regions obtain sufficient or even surplus financial resources to promote spatial spillover effects of regional financial efficiency among Chinese economic zones.
Appropriate financial development can boost regional economic growth and poverty reduction [1-3]. Investigating the financial market interconnection is crucial for understanding financial efficiency and economic growth [4]. Regional financial development and networks are drivers of regional financial efficiency and economic development [5-8]. Bank financing plays a significant role in severe information asymmetry and discriminatory legal and regulatory practices $[9,10]$. Local decentralization produces a significant spatial effect on local financial efficiency [11]. Financial developments in both credit and equity markets have greater effects on reducing financial constraints in China [12]. The transition of international financial reporting standards and regional financial freedom can improve the bank's efficiency in European Unions and Asia $[13,14]$. The performance of bank loans has an important effect on regional economic and credit risk efficiencies [15]. 
Regional financial efficiency reflects how financial institutions collect financial resources, allocate them to sectors with resource shortages, and use those resources more effectively and efficiently [16]. Cooperation among different regional financial structures can improve the overall efficiency of the financial system among economic zones [17]. Geographic proximity, intraregional financial integration, regional economic integration, and diversification benefits may have certain impacts on regional financial market integration [18, 19]. Regional financial market integration increases the information spillover network, while market interconnectedness declines when a financial crisis hits [19-23]. Intraprovincial financial disparity is positively correlated with intraprovincial economic disparity [24]. The perceived credit risks of European sovereigns exhibit high, time-varying spatial spillover effects during sovereign debt crises [25]. The spatial spillover effects of the financial network are positively correlated with important financial markets, foreign direct investment, and the inflation rate [26-29]. Eastern and western regions in China have negative spatial spillover effects of financial inclusion on the central region [30]. Financial agglomeration causes an increasing concentration of financial resources in economic zones and generates certain spatial spillover effects of internal financing efficiency on adjacent regions. The agglomeration of financial resources may influence regional financial development and promote economic growth [31, 32]. Financial market development promotes economic growth in developed and developing countries [33-35].

The regional financial efficiency among the six major regions of China exhibits a gradient difference [36]. Traditional financial development institutions exhibit greater market competition among different regions [37]. Local economic development spillover effects are an important dimension to evaluate the effects of special economic zones [38]. Different economic zones that exhibit greater divergence in the economic development level, financial market development and financial resource allocation, interregional spatial dependence, and spillover effects are important forces for promoting regional financial efficiency. The main objective of this article is to explore the spatial dependence and spillover effects of equity market, credit market, and debt market development on regional financial efficiency in eight economic zones. To the best of our knowledge, we address the gap in prior research by investigating the spatial spillover effects of the financial market on regional financial efficiency in eight economic zones. This article contributes three novelties to the existing literature. First, this article investigates the spatial layout patterns of regional financial efficiency in eight economic zones using a three-stage superefficiency (SE) data envelopment analysis (DEA) model. Second, this article reveals greater divergence in the significant effects of equity, credit, and debt markets on regional financial efficiency in eight economic zones. Third, this article expands extant knowledge on the spatial dependence of the regional financial efficiency and spatial spillover effects of three financial markets on regional financial efficiency in different economic zones.
The remainder of this article is organized as follows: Section 2 describes the three-stage SE-DEA model and a spatial econometric model. Section 3 discusses the variable selection and the data sources. Section 4 reports the statistics for regional financial efficiency in eight economic zones. Section 5 reports the spatial spillover effects of financial markets on regional financial efficiency in eight economic zones. Section 6 concludes this article.

\section{Econometric Methodology}

2.1. Three-Stage SE-DEA Model. DEA is an extensively used nonparametric linear programming approach for measuring the relative efficiency of a set of decision-making units (DMU) with multiple inputs and multiple outputs [39]. DEA model does not require enacting specific production functions and inefficiency term in advance and is barely influenced by subjective influences. The traditional DEA-CCR model created by Charnes et al. [40] is to originally evaluate the relative efficiency of DMUs with multiple inputs and outputs that assume the constant returns to scale, and the DEA-BCC model created by Banker et al. [41] is to estimate the corrected efficiency of DMUs that measures pure technical efficiency and scale efficiency with the variable returns to scale (VRS). The weakness of DEA-CCR or DEABCC models is that they cannot remove the influences of environmental factors and random errors on the DMUs efficiency [42, 43]. The three-stage superefficiency DEA model proposed by Fried et al. [44] is an extension of the DEA model. Its main advantage is accurate measurement of the operational efficiency of each decision-making unit after purging exogenous environmental impacts and statistical noise because each DMU requires the consistency of external environmental and the sensitivity of external environment and random disturbance to measure the actual regional financial efficiency.

In the first stage, the initial multiple inputs and outputs measure the efficiency level of each DMU-separated frontier for each year using the DEA model. This estimation does not consider the effects of the exogenous environment and statistical noise factors for each year. In the second stage, the multiple inputs of each DMU are corrected for variations from environmental impacts, management inefficiency, and statistical noise using the stochastic frontier analysis approach. In the third stage, the initial multiple inputs are corrected in the second stage, and the original multiple outputs measure the final SE after adjustment for purging environmental effects and statistical noise.

Andersen and Peterson proposed the SE-DEA method [45]. Assume that we have a set of $n(j=1,2, \ldots, n)$ DMUs, which produce multiple outputs by utilizing multiple inputs, and each DMU has a set of $m$ input measures and $s$ output measures, which separate frontier for each year; $x_{i o}(i=1,2, \ldots, m)$ are the $i$ th input factors, $y_{r o}(r=1,2, \ldots, s)$ are the $r$ th output factors under the condition of VRS, and the input-oriented SE for efficient $\mathrm{DMU}_{\mathrm{k}}$ can be expressed as $[11,46-48]$ 


$$
\begin{array}{ll}
\operatorname{Min} & \theta_{o}^{\text {VRS-super }} \\
& \sum_{\substack{j=1 \\
j \neq 0}}^{n} \lambda_{j}, \quad x_{i j} \leq \theta_{o}^{\text {VRS-super }} x_{i o}, \\
\text { s.t. } & \sum_{j=1}^{n} \lambda_{j}, \quad y_{r j} \geq y_{r o}, \\
& \sum_{\substack{j=1 \\
j \neq k}}^{n} \lambda_{j}=1,
\end{array}
$$

where $\lambda_{j} \geq 0$, the input $\left(x_{i j}\right)$ and output $\left(y_{r j}\right)$ factors are positive (i.e., $x_{i j} \geq 0, y_{r j} \geq 0$ ), and $\theta_{o}^{\mathrm{VRS}-\text { super }} \geq 0$ is the efficiency evaluation of DMUs. SE-DEA exhibits an increase or decrease in the proportions of a DMU's input when the efficiency value remains invariant. The SE evaluation is the same as evaluations using the traditional DEA model if the production frontier of DMUs does not achieve DEA efficiency. The SE evaluation is more than an efficiency evaluation using the traditional DEA model if the production frontier of DMUs achieves DEA efficiency. Model (1) measures the superefficiency estimations of each cross-section DMUs in the period for 2004-2016.

However, the efficiency of the first-stage DEA model is influenced by management inefficiency, exogenous environmental effects, and statistical noise. In the second stage, we present the stochastic frontier analysis approach to identify the three effects and measure the input slacks induced by management inefficiency after purging environmental effects and statistical noise. Assuming that $k(k=1,2, \ldots, p)$ are the observable environment variables, which are pooled frontier for 2004-2016, the stochastic frontier analysis is described as follows:

$$
\begin{aligned}
& s_{i k}=x_{i k}-x_{i \lambda}, \\
& s_{i k}=f^{n}\left(z_{i k}, \delta^{i}\right)+v_{i k}+\mu_{i k},
\end{aligned}
$$

where $i=1,2, \ldots, m, k=1,2, \ldots, p, s_{i k}$ refers to the input slacks, $z_{i k}=z_{i k}, z_{2 k}, \ldots, z_{p k}$ refers to the impacts of observable environmental factors, $\delta^{i}$ is the estimated parameter of environmental factors, and $f^{n}\left(z_{i k}, \delta^{i}\right)$ evaluates the feasible frontier slacks, reflecting the effects of environmental factors on the input slacks. $v_{i k}$ represents stochastic errors, indicating the influence of random interference factors on the input slack variable; $\mu_{i k}$ is management inefficiency, showing the impact of management inefficiency on input slack variables; $v_{i k}+\mu_{i k}$ represents mixed errors, and $v_{i k} \in N\left(0, \sigma_{v i}^{2}\right), \mu_{i k} \in N\left(\mu^{i}, \sigma_{i n}^{2}\right)$. In order to distinguish the impact of management inefficiency on the true financial efficiency value, we assume that all decision-making units have the same random error in the same exogenous environment. Then, each input slack variable is adjusted according to the SFA regression results. When correcting for the input slacks, the estimated parameters based on equation (2) measure the corrected input variables using Jondrow's evaluation technique [49]:

$$
x_{i k}^{C}=x_{i k}+\left[\max \left(z_{k} \delta^{i}\right)-z_{k} \delta^{i}\right]+\left[\max \left(v_{i k}\right)-v_{i k}\right],
$$

where $i=1,2, \ldots, m, k=1,2, \ldots, n, x_{i k}$ refers to the actual input variables, $x_{i k}^{C}$ refers to the corrected input variable, $\max \left(z_{k} \delta^{i}\right)-z_{k} \delta^{i}$ indicates that all the DMUs correct the same environmental effects, $\max \left(v_{i k}\right)-v_{i k}$ indicates that all the cross-section DMUs correct the same stochastic errors in the period for 2004-2016 using model 2, and all the DMUs contain the same environmental effects and statistical noise.

The corrected input variables obtained in the second stage constitute the initial input variables in equation (1). We obtain the final efficiency evaluation of each cross-section DMU after purging the environmental effects and random noise, which separate the frontier for each year.

2.2. Spatial Econometric Model. This section investigates the spatial spillover transmission effects of the equity market, credit market, and debt market on the economic-zone financial efficiency of Chinese financial markets based on the economic zone in Table 1. Here, the financial efficiencies among 30 provinces are the corrected SE financial efficiencies evaluated by the three-stage DEA model. This section presents Moran's I indices to measure the spatial autocorrelations of the SE financial efficiency in China's 30 provinces covering the period from 2004 to 2016. Moran's I indices are defined as follows $[42,50,51]$ :

$$
I=\frac{n \sum_{i=1}^{n} \sum_{j=1}^{n} w_{i j}\left(x_{i}-\bar{x}\right)\left(x_{j}-\bar{x}\right)}{\sum_{i=1}^{n} \sum_{j=1}^{n} w_{i j} \sum_{i=1}^{n}\left(x_{i}-\bar{x}\right)},
$$

where $n(1,2, \ldots, 30)$ refer to thirty provinces in China, $w_{i j}$ refers to the spatial weight matrix between province $i$ and province $j$, and $x, \bar{x}$ refer to the SE financial efficiency of the province and the average SE financial efficiency among the thirty provinces, respectively. If the regional SE financial efficiency shows a positive spatial correlation, then the value of Moran's I indices ranges from 0 to 1 . Larger Moran's I indices reflect stronger spatial positive correlations, implying that regions with similar observable values are collectively allocated in the spatial ranges. By contrast, regions with similar observable values undergo discriminated allocation in the geographical space. To measure the spatial autocorrelation of regional SE financial efficiency in various provinces, we present the economic distance weight matrix, which is defined as the reciprocal of the absolute difference of the gross domestic product (GDP) per capita between two provinces. This article introduces spatial weight matrix $w^{*}=w \times e$, here matrix $e$ is the main diagonal and the elements are all 0 . However, for nonmain diagonal $e_{i j}=\left(1 /\left|Y_{i}-\bar{Y}_{j}\right|\right)(i \neq j), Y_{i}$ is the actual GDP per capita in province $i, \bar{Y}$ is the average of actual GDP per capita in all other province $j$, and all the actual GDP per capita are converted as the constant GDP per capita in 2004.

Currently, popular spatial econometric models include the spatial error model (SEM), spatial lag model (SLM), and spatial Durbin model (SDM). The SEM supposes that spatial autocorrelation stems from the error fluctuations of neighboring regions on explained variables and investigates 
Table 1: Eight economic-zone divisions in China.

\begin{tabular}{lcc}
\hline Number & Economic zone & Included provinces \\
\hline 1 & Northeast & Liaoning, Jilin, Heilongjiang \\
2 & North coast & Beijing, Tianjin, Hebei, Shandong \\
3 & East coast & Shanghai, Jiangsu, Zhejiang \\
4 & South coast & Fujian, Guangdong, Hainan \\
5 & Middle Yellow River & Shaanxi, Shanxi, Henan, Inner Mongolia \\
6 & Middle Yangtze river & Hubei, Hunan, Jiangxi, Anhui \\
7 & Large west-south & Yunnan, Guizhou, Sichuan, Chongqing, Guangxi \\
8 & Large west-north & Gansu, Qinghai, Ningxia, Xinjiang \\
\hline
\end{tabular}

Note: this paper does not consider Hong Kong, Macao, Taiwan, and Tibet due to data unavailability.

the impacts of financial efficiency in neighboring regions under observation. The SLM supposes that spatial autocorrelation stems from explained variables and measures the influences of financial efficiency in neighboring regions on local financial efficiency [11]. The main defects of the spatial error model and spatial lag model are that the exogenous interaction effects and relative error terms do not explain the spatial distribution pattern, while the endogenous interaction effects and relative error term explain the spatial distribution pattern. The spatial Dubin model has three benefits: first, financial resources in different regions have significant spatial distribution characteristics; second, various affecting factors exhibit dynamic characteristics, and then present the spatial econometric model to measure various influencing factors; and third, the results using the spatial econometric model have good robustness $[52,53]$. To overcome these defects, we present the SDM to measure the spatial spillover effects of fiscal decentralization and financial market development on regional SE financial efficiency among eight economic zones. The spatial spillover effects of regional SE financial efficiency are influenced not only by equity market, debt market, and credit market development but also by foreign direct investment, local economic development, financial marketization, and foreign trade policy, among others. The SDM is defined as follows:

$$
F E_{i t}=c_{0}+a \sum_{j=1}^{n} w_{i j} F E_{i(t-1)}+b X_{i t}+c \sum_{j=1}^{n} w_{i j} X_{j(t-1)}+d Y_{i t}+\mu_{i}+\lambda_{t}+\xi_{i t}
$$

where $F E_{i t}$ refers to the regional SE financial efficiency; $w_{i j}$ refers to the spatial weight between provinces $i$ and $j$; $\sum_{j=1}^{n} w_{i j} F E_{i(t-1)}$ refers to the spatial lag term of regional financial efficiency; $X_{i t}$ denotes the equity market, debt market, and credit market variables; $\sum_{j=1}^{n} w_{i j} X_{j(t-1)}$ denotes the spatial lagged term of the explanatory variables; $Y_{i t}$ are the other economic control variables, and the regional SE financial efficiency, equity, debt, and credit markets and other economic variables are all panel data with cross section and 2004-2016 year; $c_{0}$ is a constant term; $a$ is a spatial correlation coefficient reflecting the interactions of regional SE financial efficiency among different regions; $b$ is the coefficient of the explanatory variable reflecting regional SE financial efficiency; $c$ is the spatial correlation coefficient of the explanatory variable; $d$ is the coefficient of other economic variables, which reflects the impact of other economic variables on regional financial efficiency; and $\mu_{i}, \lambda_{t}, \xi_{i t}$ are the regional fixed effect, time fixed effect, and residual error term, respectively.

\section{Variable Selection and Data Sources}

As shown in Table 1, we divide the 30 provinces in mainland China into eight economic zones, which are based on the regional division of economic statistics by the National Development and Reform Commission of China, economic- zone reports by the Development Research Center of the State Council of China, and the regional input-output balance sheet from 2007 provided by the State Information Center and National Bureau of Statistics of China.

This article measures provincial and regional SE financial efficiency using multiple inputs, multiple outputs, and environmental factor effects. This article selects the ratio of the conversion of savings to investment [16], the ratio of the equity market value to the GDP, the number of registered employees in financial institutions [16], and financial marketization as multiple input indicators. Added value in the financial industry, financial resources per capita, and the GDP per capita are multiple output indicators, and GDP growth, fiscal expenditure, foreign direct investment, and the openness of a region to foreign and private firms are environmental factors. The estimated details for all the variables are given in Table 2. The above data are sourced from China Economic and Social Big Data Research Platform (https://data.cnki.net/) and Wind database (https:// www.wind.com.cn/NewSite/edb.html).

To measure the spatial spillover effects of different financial market development on SE financial efficiencies in the eight economic zones, this article chooses the regional SE financial efficiency estimated by the three-stage DEA model as the explained variable and the ratio of the provincial fiscal expenditure in China's 30 provinces [54], credit financing, 
TABLE 2: Multiple inputs and outputs of the financial efficiency evaluation.

\begin{tabular}{|c|c|c|}
\hline Feature & Variable name & Variable definition \\
\hline \multirow{3}{*}{ Input variables } & $\begin{array}{l}\text { Ratio of the conversion of savings to investment } \\
\text { Ratio of the equity market value to the GDP }\end{array}$ & $\begin{array}{c}\text { Total capital formation/corresponding total savings } \\
\text { Total equity market value/GDP }\end{array}$ \\
\hline & $\begin{array}{c}\text { Number of registered employees in financial } \\
\text { institutions }\end{array}$ & Number of registered employees in financial institutions \\
\hline & Financial marketization & $\begin{array}{c}\text { Financial marketization score sourced from the wind } \\
\text { database }\end{array}$ \\
\hline \multirow{3}{*}{ Output variables } & Added value in the financial industry & $\begin{array}{l}\text { Natural logarithm of added value in the financial industry } \\
\text { (corporate financing + premium income + the savings }\end{array}$ \\
\hline & Financial resources per capita & balance \\
\hline & GDP per capita & $\begin{array}{l}\text { of a financial institution)/the number of provincial people } \\
\text { GDP/the number of provincial people }\end{array}$ \\
\hline \multirow{5}{*}{$\begin{array}{l}\text { Environmental } \\
\text { variables }\end{array}$} & GDP growth rate & $\begin{array}{c}\text { (Year-end GDP - year-beginning GDP)/year-beginning } \\
\text { GDP }\end{array}$ \\
\hline & Fiscal expenditure & Natural logarithm of fiscal expenditure \\
\hline & Foreign direct investment to GDP ratio & Total foreign direct investment/GDP \\
\hline & Foreign trade to GDP ratio & Total foreign trade value/GDP \\
\hline & Private firms' employee ratios & $\begin{array}{c}\text { Registered employee number in private firms/total } \\
\text { registered } \\
\text { employees in China }\end{array}$ \\
\hline
\end{tabular}

Note: environmental factor indicators standardize that the differences between the original data of each province and the average level of China's 30 provinces are divided by the variance of China's 30 provinces.

equity financing, and debt financing as the credit market, equity market, and debt market, respectively, which are explanatory variables. Moreover, regional foreign direct investment, regional financial marketization degree, regional GDP per capita, and regional foreign trade level are controlling variables. The definitions of the main variables in equation (5) are shown in Table 3.

All the data are obtained from the Wind database (https://www.wind.com.cn/NewSite/edb.html), Tong-huashun (Ifind) database (https://db.10jqka.com.cn/), China Stock Market \& Accounting Research (CSMAR) database (https://www.gtarsc.com/), and China Economic and Social Big Data Research Platform (https://data.cnki.net/). The regional total capital forming value, the total saving value in urban and rural regions, the GDP, financial marketization scores, added value in the financial industry, foreign direct investment, the total foreign trade value, the registered employee number in private firms, and the registered employee number in China are sourced from the Wind database. The total market values of regional equity financing are sourced from the Tong-hua-shun database, and the registered employee number in financial institutions, premium revenue, and the deposit balance in financial institutions are sourced from the CSMAR database. All the provincial data covered the period from 2004 to 2016.

\section{Statistical Descriptions of Regional Financial Efficiency}

This section first analyzes regional differences in SE financial efficiencies in China's 30 provinces and eight economic zones using the one-stage and three-stage DEA models. Table 4 shows the statistical analysis of the regional financial efficiencies in the eight economic zones. Covering the period from 2004 to 2016, the mean SE financial efficiencies in Beijing, Tianjin, Jiangsu, Shanghai, Zhejiang, Guangdong, Inner Mongolia, and Qinghai provinces are larger than 1, achieving the SE-DEA relatively effective level. However, the mean SE financial efficiencies in the other 22 provinces were less than 1 using the one-stage DEA model, which did not achieve the SE-DEA relatively effective level. Among the eight economic zones, the average one-stage SE financial efficiencies in the North coast, East coast, and South coast economic zones are greater than 1, the average one-stage SE financial efficiencies in the other five economic zones are less than 1, and the national average of the one-stage SE financial efficiencies in China's 30 provinces is equal to 0.905 , thus failing to reach the SE-DEA relatively effective level. In the one-stage DEA model, the SE financial efficiencies comprise the effects of management inefficiency, exogenous environmental effects, and statistical noise. In the second stage, stochastic frontier analysis can surge exogenous environmental effects and random statistical noise and accurately measure the SE financial efficiencies induced by operation efficiencies in China's 30 provinces. Here, we select the GDP growth rate, fiscal expenditure, the ratio of the foreign direct investment to the GDP, the ratio of the foreign trade level to the GDP, and the ratio of the registered employees in private firms to national firms as exogenous environmental factors. The empirical results of the stochastic frontier analysis indicate that most of the environmental factors have a significant impact on registered employees in financial institutions, the total market value of equity financing, and financial marketization scores in the China's 30 provinces, and the statistical results of the sigma-squared test are significant at the $1 \%$ significance level, confirming that exogenous environmental factors have significant influences on the input slacks of registered employees in financial 
Table 3: Definitions of the main variables in equation (5).

\begin{tabular}{|c|c|c|c|}
\hline Feature & Symbol & Name & Variable definition \\
\hline $\begin{array}{l}\text { Explained } \\
\text { variables }\end{array}$ & $F E_{i t}$ & $\begin{array}{l}\text { Regional financial } \\
\text { efficiency }\end{array}$ & Financial efficiency estimated by the three-stage DEA model \\
\hline \multirow{3}{*}{$\begin{array}{l}\text { Explanatory } \\
\text { variables }\end{array}$} & $C M_{i t}$ & Credit market & \multirow{3}{*}{$\begin{array}{c}\text { Natural logarithm of the year-end total deposits in financial institutions } \\
\text { Natural logarithm of the total market value of provincial equity } \\
\text { Natural logarithm of the sum of corporate bonds, local government bonds, short- } \\
\text { term financing bills, and medium-term notes }\end{array}$} \\
\hline & $E M_{i t}$ & Equity market & \\
\hline & $D M_{i t}$ & Debt market & \\
\hline \multirow{4}{*}{$\begin{array}{l}\text { Controlling } \\
\text { variables }\end{array}$} & $G D P_{i t}$ & $\begin{array}{l}\text { Regional economic } \\
\text { growth }\end{array}$ & Regional year-end GDP/total provincial people \\
\hline & $F D I_{i t}$ & $\begin{array}{l}\text { Regional foreign direct } \\
\text { investment }\end{array}$ & Natural logarithm of regional foreign direct investment \\
\hline & $F M_{i t}$ & Financial marketization & Regional financial marketization sourced from the Wind database \\
\hline & $F T_{i t}$ & $\begin{array}{l}\text { Regional foreign openness } \\
\text { level }\end{array}$ & Natural logarithm of the regional total foreign value \\
\hline
\end{tabular}

TABLE 4: Statistical descriptions of the regional financial efficiencies in the eight economic zones covering the period from 2004 to 2016.

\begin{tabular}{|c|c|c|}
\hline Economic zone & $\begin{array}{c}\text { Mean SE } \\
\text { financial efficiency by one-stage DEA (ranking) }\end{array}$ & $\begin{array}{c}\text { Mean SE } \\
\text { financial efficiency by three-stage DEA (ranking) }\end{array}$ \\
\hline 1. Northeast & 0.792 & 0.784 \\
\hline Heilongjiang & $0.728(17)$ & $0.706(17)$ \\
\hline Jilin & $0.673(20)$ & $0.678(20)$ \\
\hline Liaoning & $0.976(9)$ & $0.969(9)$ \\
\hline 2. North coast & 1.345 & 1.312 \\
\hline Beijing & $1.568(3)$ & $1.579(3)$ \\
\hline Hebei & $0.831(13)$ & $0.807(13)$ \\
\hline Shandong & $0.914(11)$ & $0.895(11)$ \\
\hline Tianjin & $2.068(1)$ & $1.966(1)$ \\
\hline 3. East coast & 1.554 & 1.524 \\
\hline Jiangsu & $1.393(5)$ & $1.398(4)$ \\
\hline Shanghai & $1.923(2)$ & $1.845(2)$ \\
\hline Zhejiang & $1.347(6)$ & $1.328(6)$ \\
\hline 4. South coast & 1.035 & 1.009 \\
\hline Fujian & $0.781(14)$ & 0.784 \\
\hline Guangdong & $1.429(4)$ & 1.387 \\
\hline Hainan & $0.896(12)$ & 0.857 \\
\hline 5. Middle Yellow River & 0.773 & 0.768 \\
\hline Henan & $0.696(18)$ & $0.683(18)$ \\
\hline Inner Mongolia & $1.116(8)$ & $1.109(8)$ \\
\hline Shanxi & $0.598(23)$ & $0.600(23)$ \\
\hline Shaanxi & $0.682 S(19)$ & $0.679(19)$ \\
\hline 6. Middle Yangtze River & 0.525 & 0.529 \\
\hline Anhui & $0.424(30)$ & $0.425(29)$ \\
\hline Hubei & $0.603(22)$ & $0.605(22)$ \\
\hline Hunan & $0.573(24)$ & $0.581(24)$ \\
\hline Jiangxi & $0.501(28)$ & $0.506(28)$ \\
\hline 7. Big West-South & 0.583 & 0.570 \\
\hline Guangxi & $0.632(21)$ & $0.612(21)$ \\
\hline Guizhou & $0.433(29)$ & $0.414(30)$ \\
\hline Sichuan & $0.565(25)$ & $0.566(25)$ \\
\hline Yunnan & $0.544(26)$ & $0.533(26)$ \\
\hline Chongqing & $0.742(16)$ & $0.726(16)$ \\
\hline 8. Big West-North & 0.876 & 0.838 \\
\hline Gansu & $0.524(27)$ & $0.517(27)$ \\
\hline Ningxia & $0.961(10)$ & $0.935(10)$ \\
\hline Qinghai & $1.264(7)$ & $1.152(7)$ \\
\hline Xinjiang & $0.753(15)$ & $0.750(15)$ \\
\hline Total & 0.905 & 0.886 \\
\hline
\end{tabular}

Note: the numbers in parentheses represent the ranks of the SE financial efficiencies in China's 30 provinces. 
institutions, equity financing, and financial marketization in China's 30 provinces. In the three-stage DEA model, we first used multiple input slacks based on equation (3) and estimated coefficients in the stochastic frontier analysis model. Then, the multiple input measures were corrected to finally obtain the three-stage SE financial efficiency evaluation using equation (1). Figure 1 shows the spatial distribution of the mean provincial three-stage SE financial efficiencies in the period from 2004 to 2016 according to rankings as high-, medium-, and low-efficiency regions. That is, the provinces are defined as high-efficiency (financial efficiency $>0.938$ ), medium-efficiency (financial efficiency $=0.652-0.938$ ), and low-efficiency (financial efficiency $=0-0.652$ ) regions. Compared with the mean SE financial efficiencies using the one-stage DEA model, the mean SE financial efficiencies increased in the Heilongjiang, Liaoning, Hebei, Shandong, Tianjin, Shanghai, Zhejiang, Guangdong, Hainan, Henan, Inner Mongolia, Shaanxi, Guangxi, Guizhou, Yunnan, Chongqing, Gansu, Ningxia, Qinghai, and Xinjiang provinces using the three-stage SE-DEA model. In contrast, the mean SE financial efficiencies in the 10 surplus provinces increased in the period from 2004 to 2016. The national average level of the three-stage SE financial efficiencies in China's 30 provinces is 0.886 , which does not correspond to the SE-DEA relatively efficient level. The average three-stage SE financial efficiencies in the East coast, North coast, and South coast economic zones are 1.524, 1.312, and 1.009, respectively, reaching the SE-DEA relatively efficient level, while the average three-stage SE financial efficiencies of the Large West-north, Northeast, Middle Yellow River, Large West-south, and Middle Yangtze River economic zones are $0.838,0.784,0.768,0.570$, and 0.529 , respectively, which do not correspond to the SE-DEA relatively efficient level. Figure 2 shows that the three-stage SE financial efficiencies in the eight economic zones exhibit significant time-varying trends: the North coast and East coast economic zones exhibit the highest three-stage SE financial efficiencies, and the Big West-South and Middle Yellow River economic zones exhibit the lowest three-stage SE financial efficiencies in the period from 2004 to 2016.

\section{Spatial Spillover Effects of the Financial Market on Regional Financial Efficiency}

5.1. Spatial Autocorrelation and the Lagrangian Multiplier (LM) Test. This section explains the spatial autocorrelation of the regional financial efficiencies in China's 30 provinces using Moran's I indices. Table 5 shows the changes in Moran's I indices of the regional financial efficiencies in the period from 2004 to 2016. The empirical results of Moran's I indices confirm that regional financial efficiency in China exhibit a positive spatial autocorrelation in the past 12 years at the $1 \%$ confidence level, and the spatial autocorrelation coefficients show greater ranges from 0.292 to 0.508 , demonstrating that the regional financial efficiencies exhibit significant correlations with the spatial distribution in China's 30 provinces influenced by the level of regional financial efficiency with similar spatial characteristics and clustering effects in the geographical space. In the period from 2004 to 2016, Moran's I indices of the regional financial efficiencies show a significant increase, ranging from 0.330 to 0.508 , and then a significant decrease, ranging from 0.508 to 0.292 . These results demonstrate that the spatial autocorrelation of the regional financial efficiencies first increases and then decreases in China's 30 provinces, implying that the influences of the regional financial efficiency in adjacent regions first increase in the period from 2004 to 2010 and then decrease in the period from 2011 to 2016. Figure 3 shows spatially scatter plots of the three-stage SE financial efficiencies in China's 30 provinces in 2004, 2010, and 2016: the horizontal axis represents the three-stage SE financial efficiency, and the vertical axis represents the spatial lag value of SE financial efficiency. Most of the provinces are located in the positive spatial correlation areas in the first and third quadrants, further indicating that the regional SE financial efficiencies exhibit significantly positive spatial spillover effects in the period from 2004 to 2016.

The empirical evidence demonstrates that the regional SE financial efficiencies exhibit significant spatial autocorrelations in China's 30 provinces. Thus, we investigated the effects of fiscal decentralization and financial market development on regional financial efficiency considering the spatial spillover factor. Before establishing the spatial econometric model, we compared two competitive models-the SLM and SEM-using the LM test. We selected the more desirable SLM or SEM with higher significance. If the LM statistics of both the SLM and SEM are significant, then the saliency of robust LM statistics is required to select the SLM or SEM. Table 6 shows the empirical results of the LM test for the financial market variable. For the spatial spillover effects of the financial market variable, the LM test of the SLM is more significant than that of the SEM, and we selected the SLM to investigate the spatial spillover effects of the financial market on the regional SE financial efficiencies in the eight economic zones.

5.2. Spatial Spillover Effects of the Financial Market on Regional Financial Efficiency. Good or bad market information has an important effect on the efficiency level of financial markets $[55,56]$. Table 7 shows the spatial spillover effects of financial market development on regional financial efficiency in the period considered. From the spatial dimensions, regional financial efficiencies in the Northeast, North coast, Middle Yangtze River, Large West-north, and Large West-south economic zones exhibit negative spatial autocorrelations at the $5 \%$ confidence level, confirming that the local financial efficiency shows a negative spatial-dependent correlation with the neighboring region's financial efficiency in the above five economic zones, and their spatial-dependent correlations exhibit significant scatter features.

Credit, bond, and equity markets exhibit different information efficiency [57]. Equity market development is positively related to regional SE financial efficiency in the East coast and South coast economic zones; negatively related to regional SE financial efficiency in the Northeast, Middle Yellow River, Middle Yangtze River, Large Westsouth, and Large West-north economic zones; and 


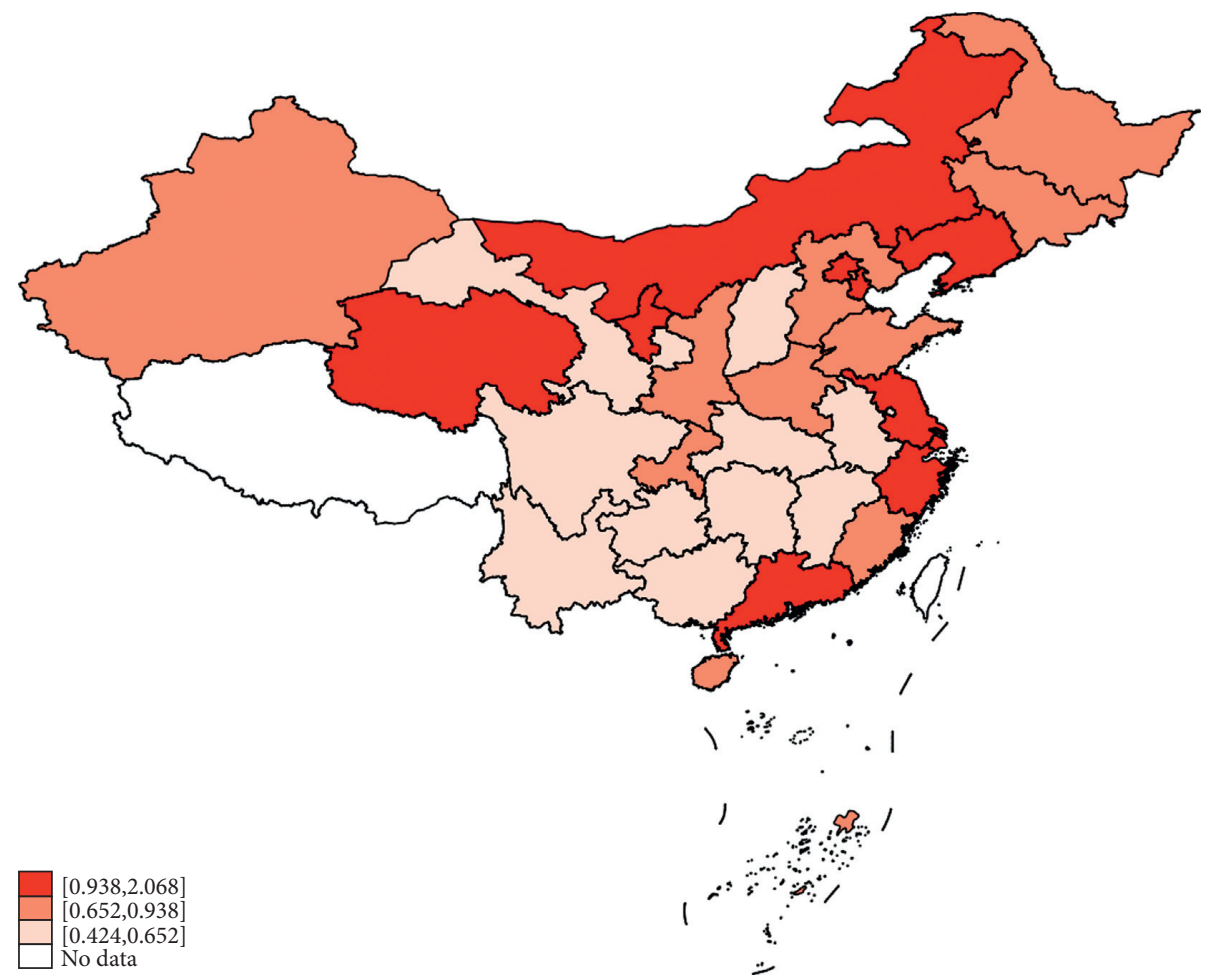

FIGURE 1: Spatial distribution of provincial SE financial efficiency using the three-stage SE-DEA model.

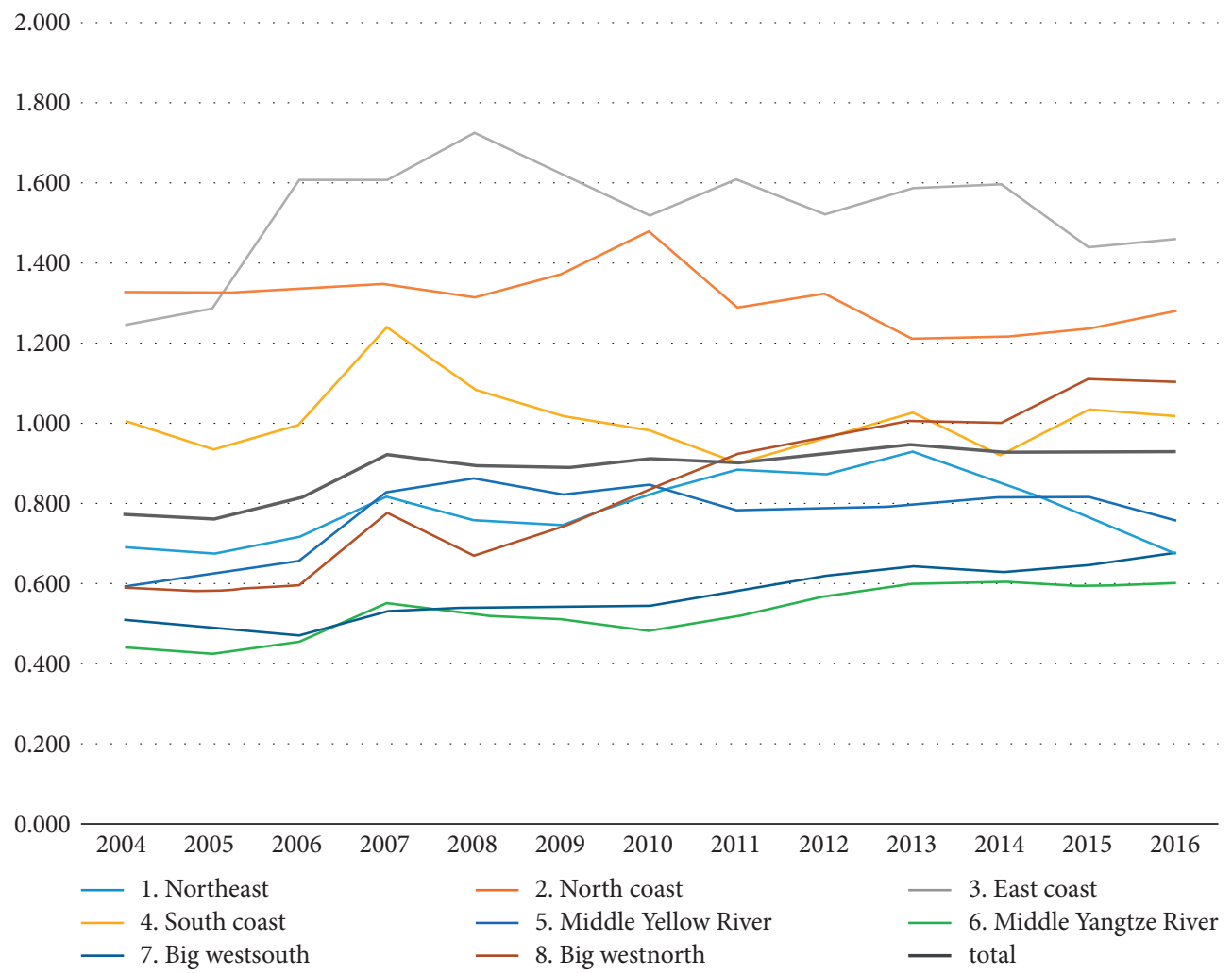

FIGURE 2: Ranges of the three-stage SE financial efficiency in the eight economic zones covering the period from 2004 to 2016.

nonsignificantly related to regional financial efficiency in the North coast economic zone at the $1 \%$ confidence level. The levels of equity market development in different economic zones exhibit greater divergence: higher levels of equity market development in the East coast and South coast economic zones can promote regional financial efficiency 


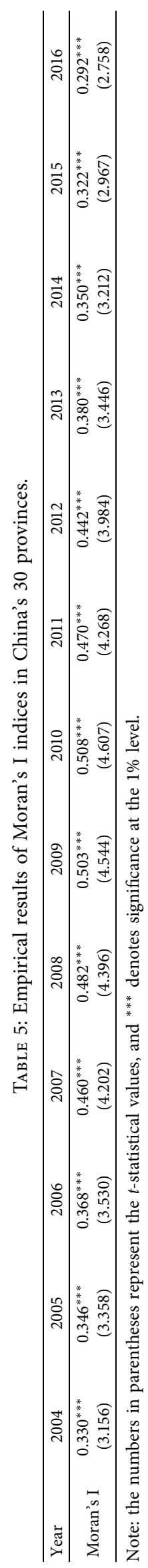



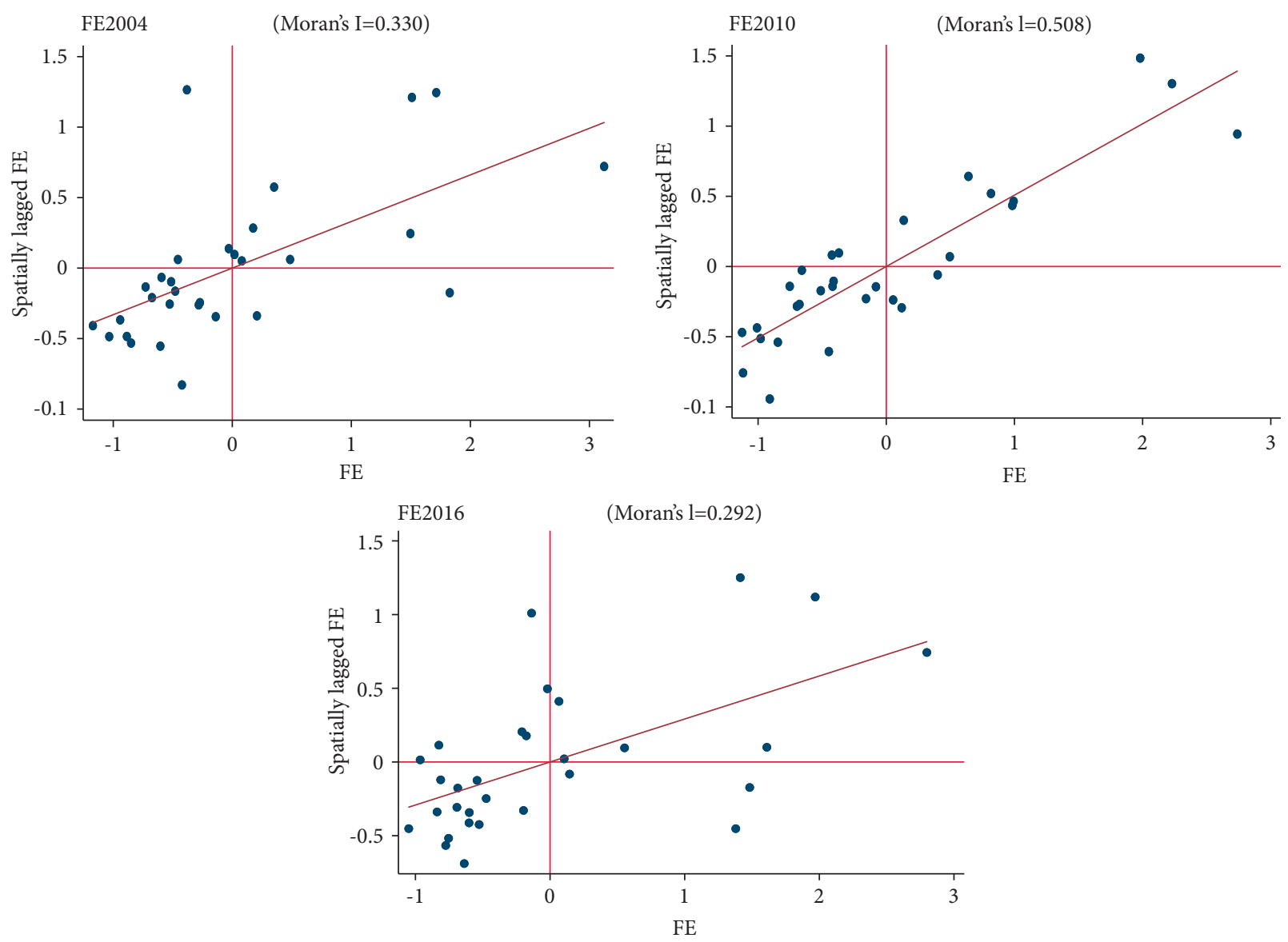

Figure 3: Spatial scatter plots of three-stage SE financial efficiencies in China's 30 provinces in 2004, 2010 , and 2016.

TABLE 6: Empirical results of the Lagrangian multiplier (LM) test.

\begin{tabular}{lcc}
\hline LM test & \multicolumn{2}{c}{ Financial market } \\
\hline LM-lag & 32.232 & $P$ value \\
LM-lag (robust) & 25.983 & 0.000 \\
LM-error & 6.439 & 0.000 \\
LM-error (robust) & 0.190 & 0.011 \\
\hline
\end{tabular}

Note: $P$ refers to the probability of the empirical results of the LM test.

improvement, while lower levels of equity market development in the Northeast, Middle Yellow River, Middle Yangtze River, Large West-south, and Large West-north economic zones may prevent regional financial efficiency improvement. In the South coast economic zone, local equity market development can generate positive spatial spillover effects on neighboring regions' financial efficiency: the higher clustering effect of the local equity market can drive neighboring regions to develop their equity market from the spatial dimension in the South coast economic zone. In the North coast, East coast, Large West-south, and Large West-north economic zones, local equity market development can generate nonsignificant spatial spillover effects on neighboring regions' financial efficiency. However, rapid local equity market development shows negative spatial spillover effects on neighboring regions' financial efficiency in the Northeast, Middle Yellow River, and Middle Yangtze River economic zones; equity market resources exhibit higher competition between local regions and neighboring regions; and certain market competitions of the equity market in these economic zones may crowd out spatial spillover effects of financial efficiency from developed regions to developing regions.

Regional location and financial crises are crucial determinants of credit market efficiency [58]. Credit market developments in the Northeast and South coast economic zones are positively related to regional financial efficiency at the $1 \%$ confidence level, while credit market developments have nonsignificant impacts on regional financial efficiency in the other six economic zones. Moreover, quick local credit 
TABLE 7: Spatial spillover effects of the financial market on regional financial efficiency in the eight economic zones.

\begin{tabular}{|c|c|c|c|c|c|c|c|c|}
\hline Variable & Northeast & North coast & East coast & South coast & $\begin{array}{c}\text { Middle } \\
\text { Yellow River }\end{array}$ & $\begin{array}{c}\text { Middle } \\
\text { Yangtze River }\end{array}$ & $\begin{array}{l}\text { Big West- } \\
\text { South }\end{array}$ & $\begin{array}{l}\text { Big West- } \\
\text { North }\end{array}$ \\
\hline$w_{i j} \times F E_{i(t-1)}$ & $\begin{array}{c}-0.366^{* *} \\
(-1.660)\end{array}$ & $\begin{array}{c}-0.497^{* * *} \\
(-6.120)\end{array}$ & $\begin{array}{c}-0.150 \\
(-0.930)\end{array}$ & $\begin{array}{c}-0.581 \\
(-4.630)\end{array}$ & $\begin{array}{c}-0.115 \\
(-0.940)\end{array}$ & $\begin{array}{c}-0.405^{* * *} \\
(-3.620)\end{array}$ & $\begin{array}{c}-0.489^{* * *} \\
(-4.890)\end{array}$ & $\begin{array}{c}-0.716^{* * * *} \\
(-9.780)\end{array}$ \\
\hline$E M_{i t}$ & $\begin{array}{c}-0.739^{* * *} \\
(-6.030)\end{array}$ & $0.014(0.250)$ & $\begin{array}{l}0.524^{* * *} \\
(10.020)\end{array}$ & $\begin{array}{c}0.567^{* * *} \\
(3.710)\end{array}$ & $\begin{array}{c}-0.456^{* * *} \\
(-9.600)\end{array}$ & $\begin{array}{c}-0.199^{* * *} \\
(-8.000)\end{array}$ & $\begin{array}{c}-0.149^{* * *} \\
(-4.450)\end{array}$ & $\begin{array}{c}-0.306^{* * *} \\
(-4.220)\end{array}$ \\
\hline$C M_{i t}$ & $\begin{array}{c}0.557^{* * *} \\
(6.240)\end{array}$ & $0.222(1.100)$ & $0.249(0.820)$ & $\begin{array}{c}1.983^{* * *} \\
(4.690)\end{array}$ & $0.485(0.620)$ & $\begin{array}{l}-0.129 \\
(-0.840)\end{array}$ & $\begin{array}{l}-0.007 \\
(-0.030)\end{array}$ & $0.361(1.090)$ \\
\hline$D M_{i t}$ & $0.005(0.370)$ & $\begin{array}{l}0.019^{* *} \\
(1.850)\end{array}$ & $\begin{array}{c}0.059^{* * *} \\
(5.930)\end{array}$ & $\begin{array}{c}-0.036^{* *} \\
(-1.890)\end{array}$ & $\begin{array}{c}-0.010 \\
(-1.360)\end{array}$ & $\begin{array}{c}0.013^{* * *} \\
(4.770)\end{array}$ & $\begin{array}{c}-0.034^{* * *} \\
(-7.510)\end{array}$ & $\begin{array}{c}-0.004 \\
(-0.160)\end{array}$ \\
\hline$w_{i j} \times E M_{i t}$ & $\begin{array}{c}-0.771^{* * *} \\
(-3.280)\end{array}$ & $0.016(0.350)$ & $1.437(1.240)$ & $\begin{array}{c}1.003^{* * *} \\
(6.990)\end{array}$ & $\begin{array}{c}-0.401^{* * *} \\
(-3.190)\end{array}$ & $\begin{array}{c}-0.066^{* *} \\
(-1.800)\end{array}$ & $0.075(0.510)$ & $\begin{array}{l}-0.407 \\
(-1.490)\end{array}$ \\
\hline$w_{i j} \times C M_{i t}$ & $\begin{array}{c}0.799^{* * *} \\
(5.980)\end{array}$ & $0.582(1.140)$ & $\begin{array}{l}-3.691 \\
(-1.200)\end{array}$ & $\begin{array}{c}3.317^{* * *} \\
(2.840)\end{array}$ & $0.550(1.120)$ & $0.268(0.930)$ & $0.261(0.840)$ & $\begin{array}{c}-0.029 \\
(-0.040)\end{array}$ \\
\hline$w_{i j} \times D M_{i t}$ & $0.009(0.170)$ & $0.013(0.530)$ & $\begin{array}{c}0.057^{* *} \\
(2.160)\end{array}$ & $\begin{array}{c}-0.042 \\
(-1.420)\end{array}$ & $\begin{array}{l}-0.022 \\
(-1.130)\end{array}$ & $\begin{array}{c}0.016^{* * *} \\
(2.780)\end{array}$ & $\begin{array}{l}-0.020 \\
(-1.050)\end{array}$ & $\begin{array}{c}-0.026 \\
(-0.700)\end{array}$ \\
\hline$G D P_{i t}$ & $\begin{array}{l}0.622^{* * *} \\
(16.440)\end{array}$ & $\begin{array}{l}0.472^{* * *} \\
(20.880)\end{array}$ & $\begin{array}{l}-0.719^{* *} \\
(-2.150)\end{array}$ & $\begin{array}{c}0.725^{* * *} \\
(5.210)\end{array}$ & $\begin{array}{l}0.941^{* *} \\
(1.670)\end{array}$ & $\begin{array}{c}0.662^{* * *} \\
(8.310)\end{array}$ & $\begin{array}{l}0.393^{* *} \\
(2.250)\end{array}$ & $\begin{array}{l}0.899^{* *} \\
(2.220)\end{array}$ \\
\hline$F D I_{i t}$ & $0.001(0.090)$ & $\begin{array}{c}-0.118 \\
(-1.590)\end{array}$ & $\begin{array}{c}-0.102 \\
(-0.510)\end{array}$ & $\begin{array}{c}-0.252 \\
(-1.400)\end{array}$ & $\begin{array}{c}0.118^{* * *} \\
(2.750)\end{array}$ & $\begin{array}{c}-0.011 \\
(-0.920)\end{array}$ & $\begin{array}{c}-0.003 \\
(-0.150)\end{array}$ & $0.005(0.190)$ \\
\hline$F M_{i t}$ & $\begin{array}{l}-0.113^{* * *} \\
(-10.760)\end{array}$ & $\begin{array}{l}-0.067^{* *} \\
(-2.030)\end{array}$ & $0.032(1.440)$ & $\begin{array}{l}-0.008 \\
(-0.180)\end{array}$ & $\begin{array}{l}-0.064 \\
(-1.070)\end{array}$ & $\begin{array}{l}-0.001 \\
(-0.080)\end{array}$ & $\begin{array}{c}0.000 \\
(-0.020)\end{array}$ & $\begin{array}{c}-0.113^{* * *} \\
(-6.660)\end{array}$ \\
\hline$F T_{i t}$ & $\begin{array}{c}-0.119^{* * *} \\
(-4.500)\end{array}$ & $\begin{array}{c}-0.347^{* * *} \\
(-3.420)\end{array}$ & $\begin{array}{c}-2.325^{* * *} \\
(-3.570)\end{array}$ & $\begin{array}{c}0.098 \\
(1.420)\end{array}$ & $\begin{array}{l}-0.040 \\
(-0.970)\end{array}$ & $\begin{array}{c}0.029^{* *} \\
(1.790)\end{array}$ & $0.010(1.220)$ & $\begin{array}{l}-0.001 \\
(-0.010)\end{array}$ \\
\hline $\begin{array}{l}\text { Year fixed } \\
\text { effect }\end{array}$ & Yes & Yes & Yes & Yes & Yes & Yes & Yes & Yes \\
\hline $\begin{array}{l}\text { Firm fixed } \\
\text { effect }\end{array}$ & Yes & Yes & Yes & Yes & Yes & Yes & Yes & Yes \\
\hline$R^{2}$ & 0.005 & 0.0826 & 0.0020 & 0.0008 & 0.2058 & 0.5219 & 0.3891 & 0.0074 \\
\hline
\end{tabular}

Note: the numbers in parentheses represent $t$-statistical values, and ${ }^{* * *}$ and ${ }^{* *}$ denote significance at the $1 \%$ and $5 \%$ significance levels, respectively.

market developments in the Northeast and South coast economic zones can generate positive spatial spillover effects on neighboring regions' financial efficiency at the $1 \%$ confidence level. Credit resource allocation is controlled by the local government, whose incentives can result in more credit resources being allocated to economic activities, thus enhancing regional financial efficiency. In the other six economic zones, credit markets show a nonsignificant spatial correlation with regional financial efficiency, local governments in the economic zones exhibit abundant credit resources, and incentive equity and bond instruments are substituted for credit resources, especially with the rapid growth of emerging instruments in developed regions and interregional financial activity lacking spatial dependence.

Different economic zones have greater divergence in debt market development. In the North coast, East coast, and Middle Yangtze River economic zones, debt market development is positively related to regional financial efficiency at the $5 \%$ confidence level. The debt market developments in the South coast and Large West-south economic zones are negatively related to regional financing efficiency at the 5\% confidence level, and debt market developments in the Northeast, Middle Yellow River, and Large West-north economic zones have a nonsignificant impact on regional financial efficiency. Fiscal decentralization, land fiscal policy, and loose economic policy will influence the rapid development of local government debts to promote regional economic activities. Larger-scale government debts may threaten fiscal sustainability, financial efficiency, and longrun economic growth [59-62]. In the East coast and Middle Yangtze River economic zones, rapid debt developments of local government exhibit positive spatial dependence with neighboring regions' financial efficiency at the 5\% confidence level, while local debt market developments in the six economic zones show nonsignificant spatial dependence with neighboring regions' financial efficiency.

Furthermore, the different economic development levels, foreign direct investments, financial marketization degrees, and foreign open policies have different impacts on regional financial efficiency in the eight economic zones. The level of economic growth in seven economic zones shows a significantly positive impact on regional financial efficiency except for the East coast economic zone, implying that greater economic growth can promote regional financial efficiency. Foreign direct investments in the Middle Yellow River economic zone have positive impacts on regional financial efficiency at the $5 \%$ confidence level, while foreign direct investments in the other seven economic zones show nonsignificant impacts on regional financial efficiency, demonstrating that foreign direct investments in most of the economic zones generate nonsignificant impacts on regional financial efficiency. Financial marketization degrees in the Northeast, North coast and Big West-North economic zones have negative impacts on regional financial efficiency at the $5 \%$ confidence level except for the other five economic zones. The foreign open policy in the Middle Yangtze River 
economic zone is positively related to regional financial efficiency at the $1 \%$ confidence level, while the foreign open policies in the Northeast, North coast, and East coast economic zones are negatively related to regional financial efficiency at the 5\% confidence level, confirming that different foreign open policies in the eight economic zones generate different impacts on regional financial efficiency.

\section{Conclusions}

Identifying the spatial dependence between financial market development and financial efficiency in the eight economic zones is crucial for policymakers to effectively formulate and implement regional financial efficiency improvements. This article explores the spatial distribution patterns and spatial spillover effects of the financial market on regional financial efficiency using exploratory spatial data analysis from a new economic geography perspective.

The empirical results demonstrate that environmental factors, such as registered employees in financial institutions, the equity market, and financial marketization degrees, have significant impacts on regional financial efficiency. The spatial distribution patterns of the three-stage SE financial efficiency show that the average financial efficiencies in the Beijing, Tianjin, Shanghai, Jiangsu, Zhejiang, Guangdong, Inner Mongolia, and Qinghai provinces are larger than 1 in the period considered, while the average financial efficiencies in the other provinces are less than 1 and do not reach the SE-DEA relatively effective level. The national average level of three-stage financial efficiency in China's 30 provinces is 0.886 , and the average financial efficiencies in the East coast, North coast, and South coast economic zones are 1.524, 1.312, and 1.009, respectively, reaching the SE-DEA relatively efficient level. The average financial efficiencies in the Large West-north, Northeast, Middle Yellow River, Large West-south, and Middle Yangtze River economic zones are 0.838, 0.784, 0.768, 0.570, and 0.529 , respectively, reaching the SE-DEA relatively inefficient level.

Moran's I indices confirm that regional financial efficiency in China shows positive spatial clustering dependence at the $1 \%$ confidence level, and Moran's I indices of regional financial efficiency in adjacent regions have larger ranges from 0.292 to 0.508 , first increasing in the period from 2004 to 2010 and then decreasing in the period from 2011 to 2016. The empirical results confirm that regional financial efficiency in the Northeast, North coast, Middle Yellow River, Middle Yangtze River, Large West-south, and West-north economic zones exhibits negative spatial spillover effects at the $5 \%$ confidence level. Equity markets in the East coast and South coast economic zones exhibit significantly positive influences on regional financial efficiency, and equity markets in the Northeast, Middle Yellow River, Middle Yangtze River, Large West-south, and Large West-north economic zones exhibit significantly negative influences on regional financial efficiency. Credit markets in the Northeast and South coast economic zones exhibit significant positive impacts on regional financial efficiency; debt markets in the North coast, East coast, and Middle Yangtze River economic zones exhibit significant positive impacts on regional financial efficiency; and debt markets in South coast and Large West-south economic zones exhibit significant negative impacts on regional financial efficiency. Local equity markets in the Northeast, Middle Yellow River, and Middle Yangtze River economic zones show negative spatial spillover effects on neighboring regions' financial efficiency, while the local equity market in the South coast economic zone shows positive spatial spillover effects on neighboring regions' financial efficiency at the 5\% confidence level. Local credit markets in the Northeast and South coast economic zones exhibit positive spatial spillover effects on neighboring regions' financial efficiency, and local debt markets in the East coast and Middle Yangtze River economic zones exhibit positive spatial spillover on neighboring regions' financial efficiency at the $5 \%$ confidence level. Furthermore, the economic development level, foreign direct investment, financial marketization degree, and foreign open policy have different impacts on the regional financial efficiency in the eight economic zones.

\section{Data Availability}

The data used to support the findings of this study are available from the authors upon request.

\section{Ethical Approval}

This article does not contain any studies with human participants or animals performed by any of the authors.

\section{Disclosure}

The authors would like to declare that this paper is original unpublished work, and has not been submited to any other journals.

\section{Conflicts of Interest}

The authors declare no conflicts of interest.

\section{Acknowledgments}

The authors are grateful for the research support from the Shanghai Soft Science Foundation "Science and Technology Innovation Actions" (21692108000), Shanghai Planning of Philosophy and Social Science (2020BJB011), and National Natural Science Foundation of China (71673236).

\section{References}

[1] C. H. Shen, C. C. Lee, S. W. Chen, and Z. Xie, "Roles played by financial development in economic growth: application of the flexible regression model," Empirical Economics, vol. 41, no. 1, pp. 103-125, 2011.

[2] M. Sehrawat and A. K. Giri, "The impact of financial development, economic growth, income inequality on poverty: evidence from India," Empirical Economics, vol. 55, no. 4, pp. 1585-1602, 2018.

[3] L. L. Jiang, H. Wang, A. H. Tong, Z. F. Hu, X. L. Zhang, and Y. F. Wang, "The measurement of green finance development 
index and its poverty reduction effect: dynamic panel analysis based on improved entropy method," Discrete Dynamics in Nature and Sciety, vol. 2020, pp. 1-15, 2010.

[4] D. P. Louzis, "Measuring spillover effects in euro area financial markets: a disaggregate approach," Empirical Economics, vol. 49, no. 4, pp. 1367-1400, 2015.

[5] M. von Ehrlich and T. Seidel, "Regional implications of financial market development: industry location and income inequality," European Economic Review, vol. 73, pp. 85-102, 2015.

[6] K. H. Hu, W. J. Guo, and G. H. Tzeng, "Improving China's regional financial center modernization development using a new hybrid MADM model," Technological and Economic Development of Economy, vol. 24, no. 2, pp. 429-466, 2018.

[7] D. Asteriou and K. Spanos, "The relationship between financial development and economic growth during the recent crisis: evidence from the EU," Finance Research Letters, vol. 28, pp. 238-245, 2019.

[8] F. H. Pan, C. Yang, and H. Wang, "Linking global financial networks with regional development: a case study of Linyi, China," Regional Studies, vol. 4, pp. 1-15, 2019.

[9] W. Zhou, "Bank financing in China's private sector: the payoffs of political capital," World Development, vol. 37, no. 4, pp. 787-799, 2009.

[10] A. J. Glass and K. Kenjegalieva, “A spatial productivity index in the presence of efficiency spillovers: evidence for U.S. banks, 1992-2015," European Journal of Operational Research, vol. 273, no. 3, pp. 1165-1179, 2019.

[11] J. Liu, X. Hu, and H. Tang, "Fiscal decentralization and regional financial efficiency: an empirical analysis of spatial durbin model," Discrete Dynamics in Nature and Society, vol. 2016, Article ID 6597138, 14 pages, 2016.

[12] J. Hu, G. Li, and F. Zhu, "Regional financial developments and research and development investment-cash flow sensitivity: evidence on Chinese public high-tech companies," International Review of Finance, vol. 17, no. 4, pp. 627-643, 2017.

[13] K. L. Lin, A. T. Doan, and S. C. Doong, "Changes in ownership structure and bank efficiency in Asian developing countries: the role of financial freedom," International Review of Economics \& Finance, vol. 43, pp. 19-34, 2016.

[14] A. I. Dimitras, C. Gaganis, and F. Pasiouras, "Financial reporting standards' change and the efficiency measures of EU banks," International Review of Financial Analysis, vol. 59, pp. 223-233, 2018.

[15] J. P. Boussemart, H. Leleu, and Z. Shen, "Decomposing banking performance into economic and credit risk efficiencies," European Journal of Operational Research, vol. 277, pp. 719-726, 2019.

[16] M. Hu, J. Zhang, and C. C. Chao, "Regional financial efficiency and its non-linear effects on economic growth in China," International Review of Economics and Finance, vol. 59, pp. 193-206, 2019.

[17] J. Li, Z. J. Fan, and Q. Y. Xie, “The coupling effect of different financial architecture embedded in each other-based on panbeibu gulf regional financial cooperation empirical," Economic Research Journal (China), vol. 12, pp. 69-82, 2012.

[18] N. A. Boamah, "Regional and global market integration of African financial markets," African Review of Economics and Finance-AREF, vol. 8, no. 2, pp. 234-268, 2016.

[19] A. Rughoo and K. F. You, "Asian financial integration: global or regional-evidence from money and bond markets," International Review of Financial Analysis, vol. 48, pp. 419-434, 2016.
[20] W. H. Huang and Z. X. Chen, "Modeling regional linkage of financial markets," Journal of Economic Behavior \& Organization, vol. 99, pp. 18-31, 2014.

[21] X. Y. Liu, H. Z. An, H. J. Li, Z. H. Chen, S. D. Feng, and S. B. Wen, "Features of spillover networks in international financial markets: evidence from the G20 countries," Physica A, vol. 479, pp. 265-278, 2017.

[22] B. Chowdhury, M. Dungey, and M. Kangogo, "The changing network of financial market linkages: the Asian experience," International Review of Financial Analysis, vol. 64, pp. 71-92, 2019.

[23] R. Dias, J. V. da Silva, and A. Dionísio, "Financial markets of the LAC region: does the crisis influence the financial integration," International Review of Financial Analysis, vol. 63, pp. 160-173, 2019.

[24] K. Zou and J. He, "Intra-provincial financial disparity, economic disparity, and regional development in China: evidence from prefecture-level city data," Emerging Market Finance and Trade, vol. 54, no. 13, pp. 3063-3079, 2018.

[25] F. Blasques, S. J. Koopmana, A. Lucas, and J. Schaumburg, "Spillover dynamics for systemic risk measurement using spatial financial time series models," Journal of Econometrics, vol. 195, pp. 211-223, 2016.

[26] C. K. Choong, "Does domestic financial development enhance the linkages between foreign direct investment and economic growth," Empirical Economics, vol. 42, pp. 819-834, 2012.

[27] J. Huang, W. S. Zhang, and W. H. Ruan, "Spatial spillover and impact factors of the internet finance development in China," Physica A, vol. 527, pp. 1-12, 2019.

[28] W. P. Zhang, X. T. Zhuang, and Y. S. Li, "Dynamic evolution process of financial impact path under the multidimensional spatial effect based on G20 financial network," Physica A, vol. 532, pp. 1-15, 2019.

[29] Y. T. Bian, Y. Wang, and L. Xu, "Systemic risk contagion in reconstructed financial credit network within banking and firm sectors on debtrank based model," Discrete Dynamics in Nature and Science, vol. 2020, Article ID 8885657, 14 pages, 2020.

[30] B. Zhu, J. He, and S. T. Zhai, "Does financial inclusion create a spatial spillover effect between regions- evidence from China," Emerging Markets Finance and Trade, vol. 55, no. 5, pp. 980-997, 2019.

[31] C. H. Ye, C. W. Sun, and L. T. Chen, "New evidence for the impact of financial agglome -ration on urbanization from a spatial econometrics analysis," Journal of Cleaner Production, vol. 200, pp. 65-73, 2018.

[32] Y. H. Yu, W. W. Xie, Y. S. Dong, J. C. Xu, and S. Wang, "The influence of factor endowment on financial industry agglomeration- an empirical study based on the financial characteristic town," Journal of Interdisciplinary Mathematics, vol. 21, no. 5, pp. 1327-1332, 2018.

[33] J. Klomp, "Does government ideology shake or shape the public finances-empirical evidence of disaster assistance," World Development, vol. 118, pp. 118-127, 2019.

[34] I. Sobiech, "Remittances, finance and growth: does financial development foster the impact of remittances on economic growth," World Development, vol. 113, pp. 44-59, 2019.

[35] C. Wang, X. Y. Zhang, and P. Ghadimi, "The impact of regional financial development on economic growth in Beijing-Tianjin-Hebei region: a spatial econometric analysis," Physica A, vol. 521, pp. 635-648, 2019.

[36] Q. Zhang, Z. Z. Xu, T. J. Feng, and J. Jiao, "A dynamic stochastic frontier model to evaluate regional financial efficiency: evidence 
from Chinese county-level panel data," Europran Journal of Operational Research, vol. 241, pp. 907-916, 2015.

[37] C. Humphrey and K. Michaelowa, "China in Africa: competition for traditional development finance institutions," World Development, vol. 120, pp. 15-28, 2019.

[38] M. Alkon, "Do special economic zones induce developmental spillovers-evidence from India's states," World Development, vol. 107, pp. 396-409, 2018.

[39] F. Fall, A. Akim, and H. Wassongma, "DEA and SFA research on the efficiency of microfinance institutions: a meta-analysis," World Development, vol. 107, no. 7, pp. 176-188, 2018.

[40] A. Charnes, W. W. Cooper, and E. Rhodes, "Measuring the efficiency of decision making units," European Journal of Operation Research, vol. 2, pp. 429-444, 1978.

[41] R. D. Banker, A. Charnes, and W. W. Cooper, "Some models for estimating technical and scale inefficiencies in data development analysis," Management Science, vol. 30, pp. 1078-1092, 1984.

[42] P. Xu, F. Luo, Z. Y. Zhang, and H. Y. Xu, "Research on innovation efficiency of listed companies in development zone based on the three-stage DEA-Tobit model: a case study of Hubei province," Discrete Dynamics in Nature and Sciety, vol. 2020, Article ID 1838469, 12 pages, 2020.

[43] W. Z. Zhou and W. H. Yu, "Regional variation in the carbon dioxide emission efficiency of construction industry in China: based on the three-stage DEA model," Discrete Dynamics in Nature and Society, vol. 8, pp. 1-13, 2021.

[44] H. O. Fried, C. A. K. Lovell, S. S. Schmidt, and S. Yaisawarng, "Accounting for environmental effects and statistical noise in data envelopment analysis," Journal of Productivity Analysis, vol. 17, pp. 157-174, 2002.

[45] P. Andersen and N. C. Petersen, "A procedure for ranking efficient units in data envelopment analysis," Management Science, vol. 39, pp. 1261-1264, 1993.

[46] H. S. Lee, C. W. Chu, and J. Zhu, "Super-efficiency DEA in the presence of infeasibility," European Journal of Operational Research, vol. 212, pp. 141-147, 2011.

[47] Q. Hou, M. O. Wang, and X. Zhou, "Improved DEA cross efficiency evaluation method based on ideal and anti-ideal points," Discrete Dynamics in Nature and Sciety, vol. 2018, Article ID 1604298, 10 pages, 2018.

[48] P. Wanke, M. A. K. Azad, A. Emrouznejad, and J. Antunes, “A dynamic network DEA model for accounting and financial indicators: a case of efficiency in MENA banking," International Review of Economics and Finance, vol. 61, pp. 52-68, 2019.

[49] J. Jondrow, "On the estimation of technique inefficiency in the stochastic frontier production function model," Journal of Econometrics, vol. 19, pp. 233-238, 1982.

[50] L. Anselin, "Local indicators of spatial association-LISA," Geographical Analysis, vol. 27, no. 2, pp. 93-115, 1995.

[51] S. Shao, X. Li, J. H. Cao, and L. L. Yang, "China's economic policy choices for governing smog pollution based on spatial spillover effects," Economic Research Journal (China), vol. 9, pp. 73-88, 2016.

[52] Y. Yang, G. Niu, D. Tang, and M. Zhu, "Does environmental regulation affects the introduction of FDI in China?-empirical research based on spatial durbin model," Polish Journal of Environmental Studies, vol. 28, no. 1, pp. 415-424, 2019.

[53] Y. H. Yang, D. L. Tang, and P. Peng Zhang, "Double effects of environmental regulation on carbon emissions in China: empirical research based on spatial econometric model," Discrete Dynamics in Nature and Society, vol. 9, pp. 1-15, 2020.
[54] Y. S. Xu and B. Y. Qiao, "Measuring degrees of fiscal decentralization: theory and China experience from 1985 to 2007," Economic Research Journal (China), vol. 10, pp. 4-13, 2012.

[55] T. Choudhry and R. Jayasekera, "Level of efficiency in the UK equity market: empirical study of the effects of the global financial crisis," Review of Quantitative Finance and Accounting, vol. 44, no. 2, pp. 213-242, 2015.

[56] P. C. Ma, D. Y. Li, and S. Li, "Efficiency and cross-correlation in equity market during global financial crisis: evidence from China," Physica A, vol. 444, pp. 163-176, 2016.

[57] F. M. Siokis, "Credit market jitters in the course of the financial crisis: a permutation entropy approach in measuring informational efficiency in financial assets," Physica A, vol. 499, pp. 266-275, 2018.

[58] A. M. Campillo, Y. F. Santos, and M. P. S. Fernandez, "How well have social economy financial institutions performed during the crisis period-exploring financial and social efficiency in Spanish credit unions," Journal of Business Ethics, vol. 151, no. 2, pp. 319-336, 2018.

[59] A. R. Ghosh, J. I. Kim, E. G. Mendoza, J. D. Ostry, and M. S. Qureshi, "Fiscal fatigue, fiscal space and debt sustainability in advanced economies," Economic Journal, vol. 123, no. 566, pp. 4-30, 2011.

[60] C. M. Reinhart and K. S. Rogoff, "From financial crash to debt crisis," American Economics Review, vol. 101, no. 5, pp. 997-1032, 2011.

[61] G. Cafiso, "Debt developments and fiscal adjustment in the EU,” Intereconomics, vol. 47, no. 1, pp. 61-72, 2012.

[62] Y. Chen and L. Liang, "Super-efficiency DEA in the presence of infeasibility: one model approach," European Journal of Operational Research, vol. 213, pp. 359-360, 2011. 